
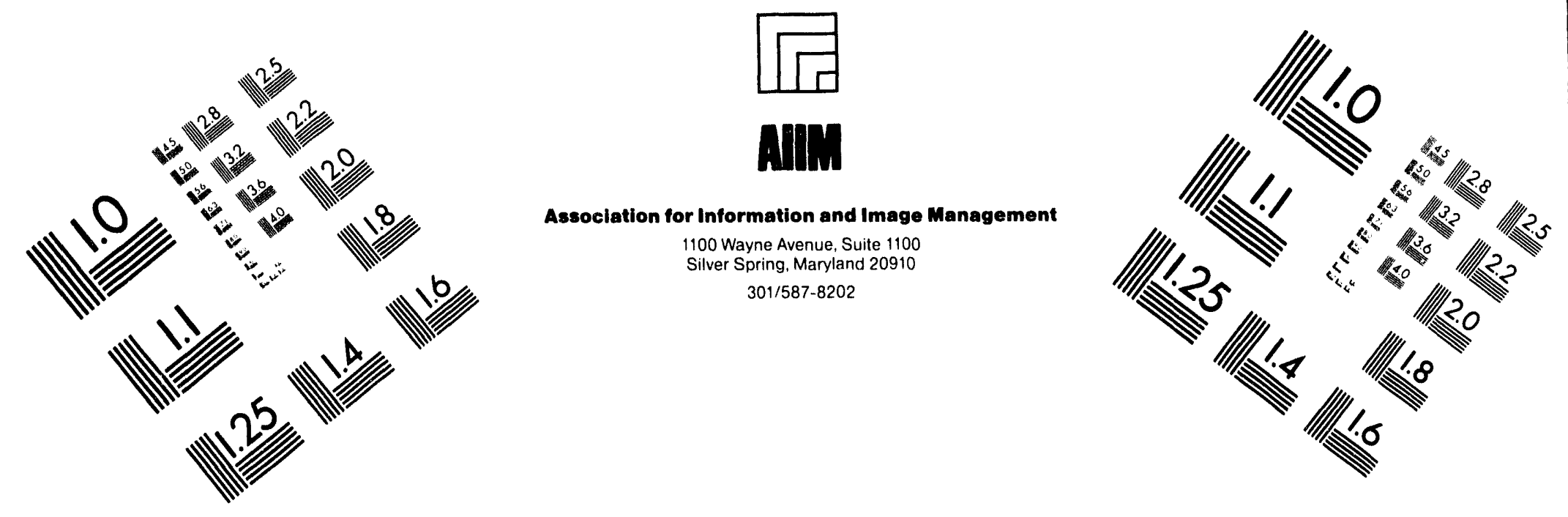

Centimeter

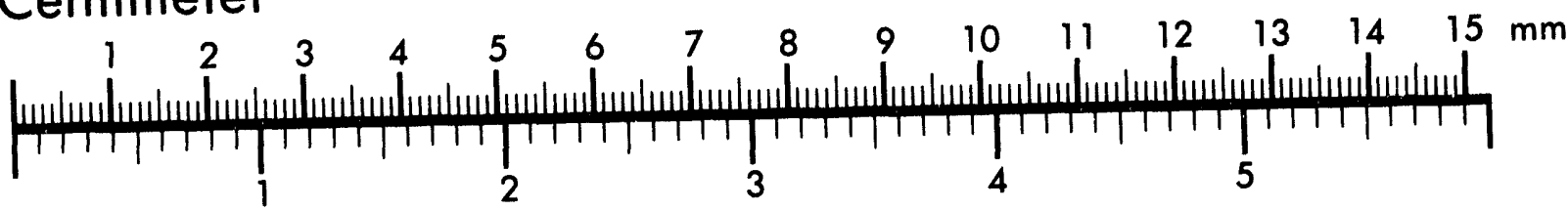

Inches
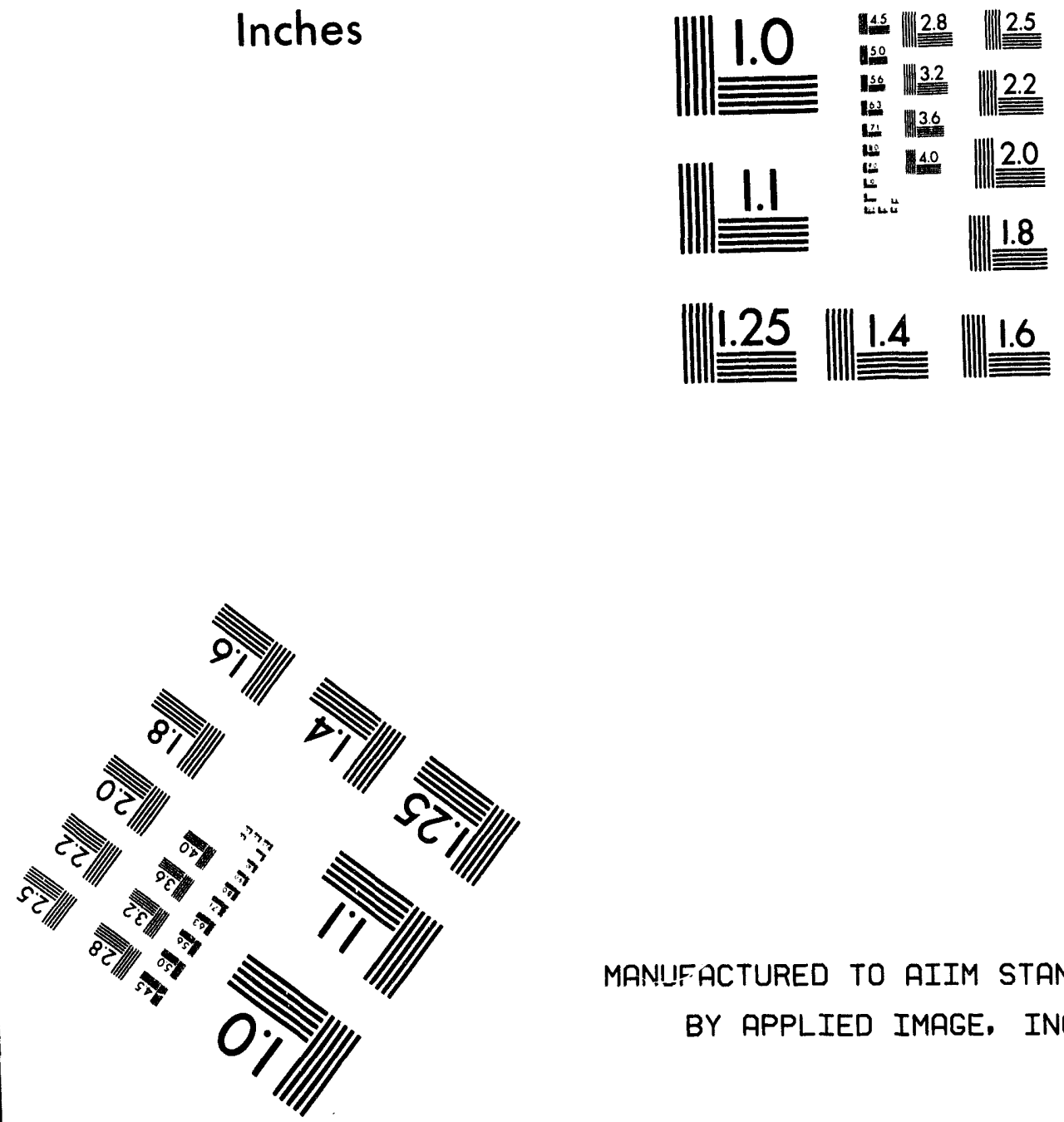

MANIIFACTURED TO AIIM STANDARDS

BY APPLIED IMAGE, INC.

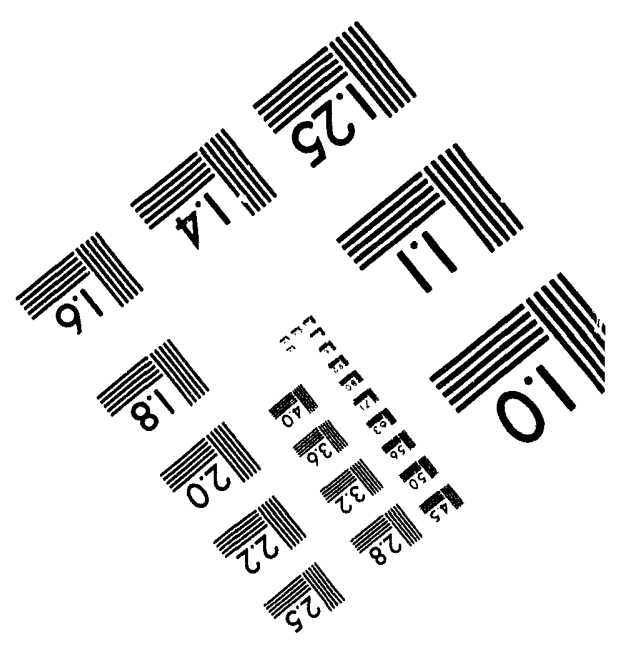



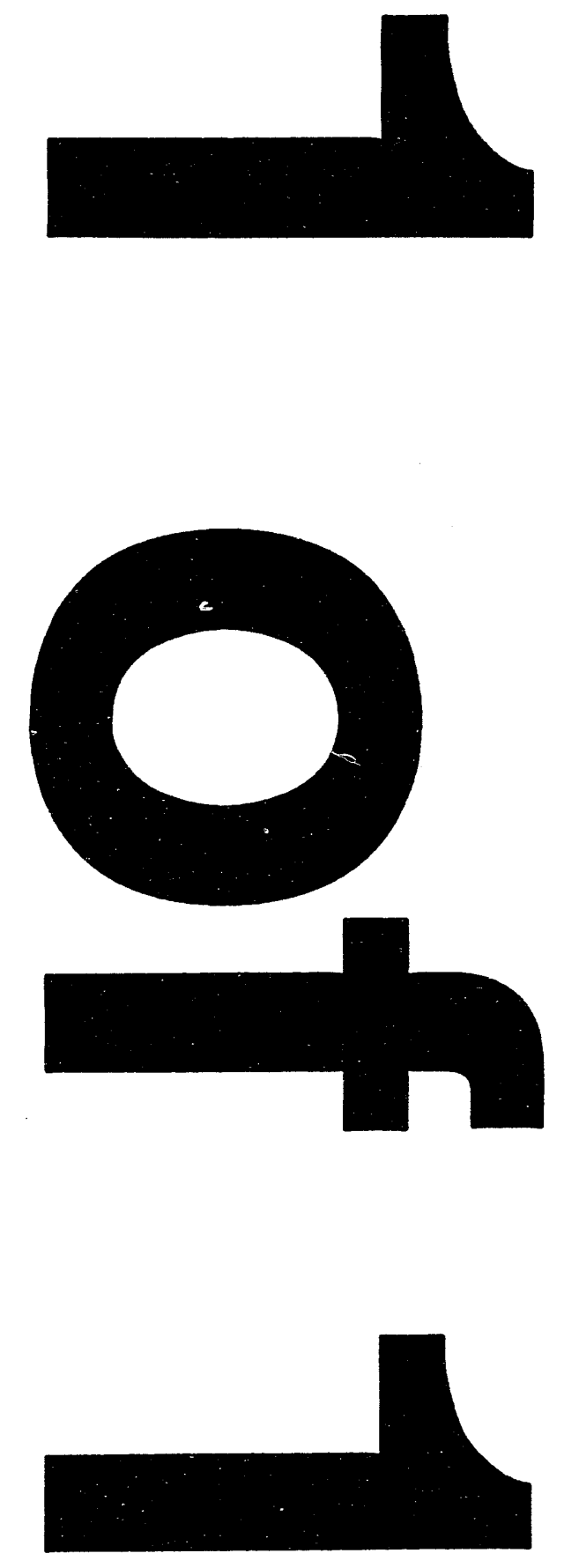


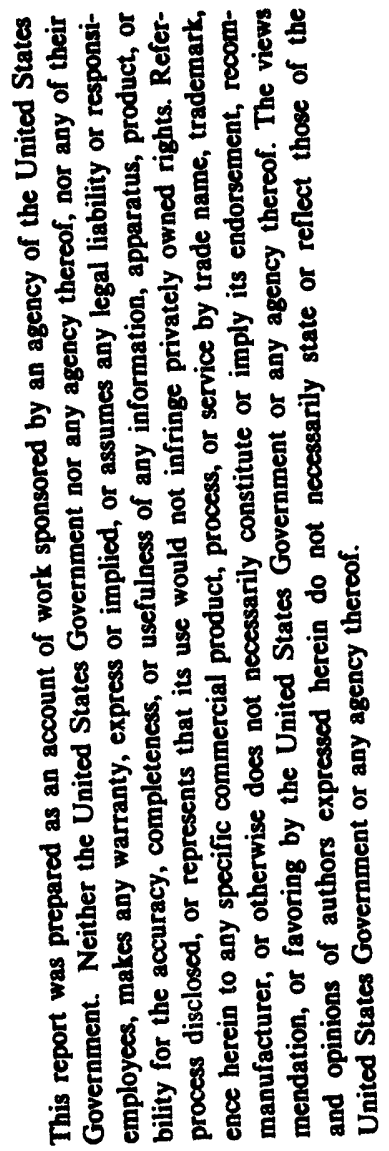

\author{
Author(s): \\ C. A. Beard, TSA-3 \\ R. R. Bracht, ESA-6 \\ J. J. Buksa, TSA-12 \\ W. Chaves, ESA-4 \\ B. G. DeVolder, X-5 \\ J. J. Park, TSA-12 \\ R. B. Parker, ESA-13 \\ C. Pillai, AOT-7 \\ E. J. Pitcher, LAINSCE \\ R. C. Potter, ESA-4
}

Submitted to:
R. S. Reid, ESA-13

G. J. Russell, LANSCE

D. A. Trujillo, ESA-4

O. A. Vela, ESA-6

F. Venneri, P-17

D. J. Weinacht, ESA-13

S. A. Wender, P-17

W. B. Wilson, T-2

K. A. Woloshun, ESA-13

H. O'Brien, P-DO

\section{International Conference on Accelerator--Driven Transmutation Technologies and Applications}

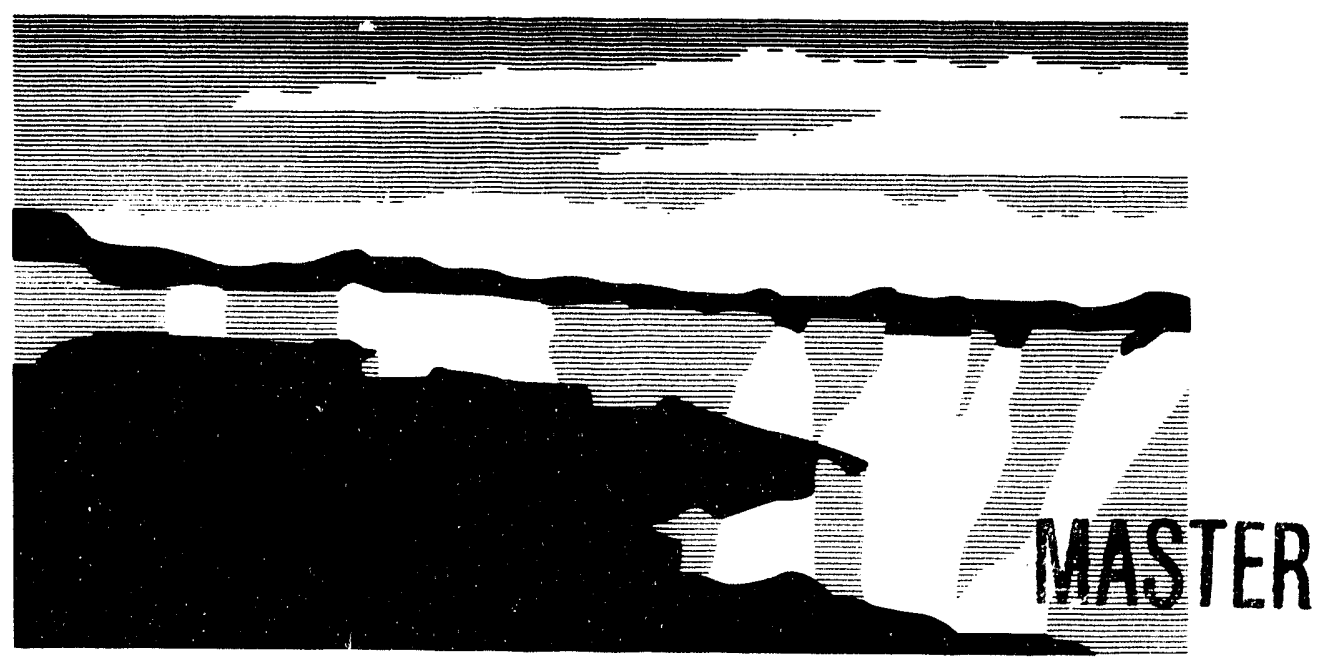

Los Alamos National Laboratory, an affirmative action/equal opportunity employer, is operated by the University of California for the U.S. Department of Energy under contract W-7405-ENG-36. By acceptance of this article, the publisher recognizes that the U.S. Government retains a nonexclusive, royalty-free license to publish or reproduce the published form of this contribution, or to allow others to do so, for U.S. Government purposes. The Los Alamos National Laboratory requests that the publisher identhy this article as work performed under the auspices of the U.S. Department of Energy. 


\title{
Flowing Lead Spallation Target Design for Use in an ADTT Experimental Facility Located at LAMPF
}

\author{
C. A. Beard, R. R. Bracht, J. J. Buksa, W. Chaves, B. G. DeVolder, H. O'Brien, J. J. Park, \\ R. B. Parker, C. Pillai, E. J. Pitcher R. C. Potter, R. S. Reid, G. J. Russell, D. A. Trujillo, \\ O. A. Vela, F. Venneri, D. J. Weinacht, S. A. Wender, W. B. Wilson, K. A. Woloshun \\ Los Alamos National Laboratory \\ Los Alamos, NM 87545
}

\begin{abstract}
A conceptual design has been initiated for a flowing lead spallation target for use in an ADTT experimental facility located at LAMPF. The lead is contained using $\mathrm{Nb}-1 \mathrm{Zr}$ as the structural material. This material was selected based on its favorable material properties as well as its compatibility with the flowing lead. Heat deposited in the lead and the $\mathrm{Nb}-1 \mathrm{Zr}$ container by the $800-\mathrm{MeV}, 1-\mathrm{mA}$ beam is removed by the flowing lead and transferred to helium via a conventional heat exchanger.
\end{abstract}

The neutronic, thermal hydraulic, and stress characteristics of the system have been determined. In addition, a module to control the thaw and freeze of the lead has been developed and incorporated into the target system design. The entire primary target system (spallation target, thaw/freeze system, and intermediate heat exchanger) has been designed to be built as a contained module to allow easy insertion into an experimental ADTT blanket assembly and to provide multip'e levels of containment for the lead.

For the 800-MeV LAMPF beam, the target delivers a source of approximately 18 neutrons/proton. A total of $540 \mathrm{~kW}$ are deposited in the target. The lead temperature ranges from 400 to $500 \mathrm{C}$. The peak structural heating occurs at the beam interface, and the target is designed to maximize cooling at this point. An innovative thin-window structure has been incorporated that allows direct, convective cooling of the window by the inlet flowing lead. Safe and reliable operation of the target has been maximized through simple, robust engineering.

\section{INTRODUCTION}

The design of a high-power spallation target is essential for almost all Accelerator-Driven Transmutation Technologies (ADTT). Although the optimal target material and target design is strongly dependent on the system in which it is to be used (and its associated goals), many ADTT applications (Accelerator Transmutation of Waste (ATW), Accelerator-Based Conversion of plutonium (ABC), Accelerator-Driven Energy Production (ADEP)) would benefit from using a simple monolithic target design. To avoid large parasitic neutron losses in such a design, the use of a low-neutron-absorbing material (such as lead, bismuth, or a lead-bismuth eutectic) is required. Additionally, the low melting points of these materials and the high target power densities needed for the ADTT applications require that the target material be used in liquid form.

The design and operation of a flowing-liquid-metal spallation target presents many technical challenges with regard to material compatibilities, heat transport from the target material as well as its structural container, handling of the liquid metal, as well as obtaining the required target lifetime for use in an ADTT system. All of these issues must be dealt with while still delivering the required neutron source to the transmutation system. In order to resolve these issues, an effort has been initiated to design and operate an experimental flowing lead spallation target at the Los Alamos Meson Physics Facility (LAMPF). This effort includes the design of the primary target and required subsystems (pump, heat exchanger, secondary heat transport system, lead freeze/thaw control, lead injection/removal system, and associated instrumentation), as well as a series of developmental experiments (material irradiation, flow modeling, lead handling, etc.) ultimately leading to the operation of the flowing lead spallation target in the LAMPF proton beam. 


\section{PRIMARY TARGET DESIGN}

A diagram of the primary target is shown in Fig. 1. The lead is contained using $\mathrm{Nb}-1 \mathrm{Zr}$ as the structural material. This material was selected based on its favorable material properties as well as its compatibility with the flowing lead[1]. The 800-MeV, 1-mA LAMPF proton beam impinges upon the target with a beam distribution assumed to be a Gaussian with a $1.25-\mathrm{cm}$ standard deviation which is similar to the beam distribution incident on the Los Alamos Neutron Scattering Center (LANSCE) spallation target. The actual beam distribution will ultimately depend on the physical location of the target along the beam line, but in no case will be smaller than stated above. The LAHET Code System (LCS)[2] was used to characterize the neutron source. This configuration produces a total neutron source (leakage) of 18.13 neutrons/proton. The leakage distribution is given in Table 1.

Table 1. Calculated Distribution of Leakage Neutrons from Spallation Target

Target Face

Leakage (neutrons/proton)

\begin{tabular}{lc}
\hline Front & 6.58 \\
Rear & 2.23 \\
Radial & 9.32 \\
Total & 18.13 \\
\hline
\end{tabular}

Flow-characterization within the target has been performed. The flow enters vertically from the top into an inlet plenum located in the outer radial region at the rear of the target. The flow is injected into the center core of the target where it is forced through the hole in the second window and upon the center of the first window, where it is then redirected outward between the two windows into the outlet plenum and upward out of the primary target region. It should be noted that although both the primary structural interface between the target and beam, as well as the flow guide behind it are referred to as "windows", the actual window confining the vacuum along the beam line will be the typical water-cooled inconel-718 window currently used at LAMPF. For a target employed in an ADTT system, it is envisioned that the first window will be the actual vacuum interface for the beam line, but this will not be the case for the experimental assembly. The flow distribution between the two windows is shown in Fig. 2 . Two recirculation zones exists: one between the two windows, and a second in the outlet plenum. Neither of these is expected to present a problem; however, efforts are underway to reduce or eliminate this behavior.

Stress analyses were performed on the primary target. At a temperature of $1250 \mathrm{~K}$, the yield stress of $\mathrm{Nb}-1 \mathrm{Zr}$ is $10 \mathrm{ksi}$. All stresses in the target are maintained below a value of $5 \mathrm{ksi}$, which gives a safety factor of two, even at this elevated temperature.

\section{HEAT REMOVAL SYSTEM}

Heat removal is accomplished by circulating the lead via an electromagnetic (EM) pump through an intermediate heat exchanger which uses helium as the secondary working fluid. The total power deposition was computed using the LCS and was found to be $540 \mathrm{~kW}$. However, for conservatism, the primary and secondary heat transport systems were designed to remove 800 $\mathrm{kW}$. This translates into a required mass flow rate of $52 \mathrm{~kg} / \mathrm{s}$. A systems diagram which shows the temperatures and pressures throughout both the primary and secondary loops is shown in Fig. 3.

Heat removal from the structural container is accomplished through convective cooling using the flowing lead. This places the most stressing heat removal requirements on the first window which is directly exposed to the beam. Using the LCS, a spatially dependent power distribution in the first window was calculated by dividing this structure into a series of 


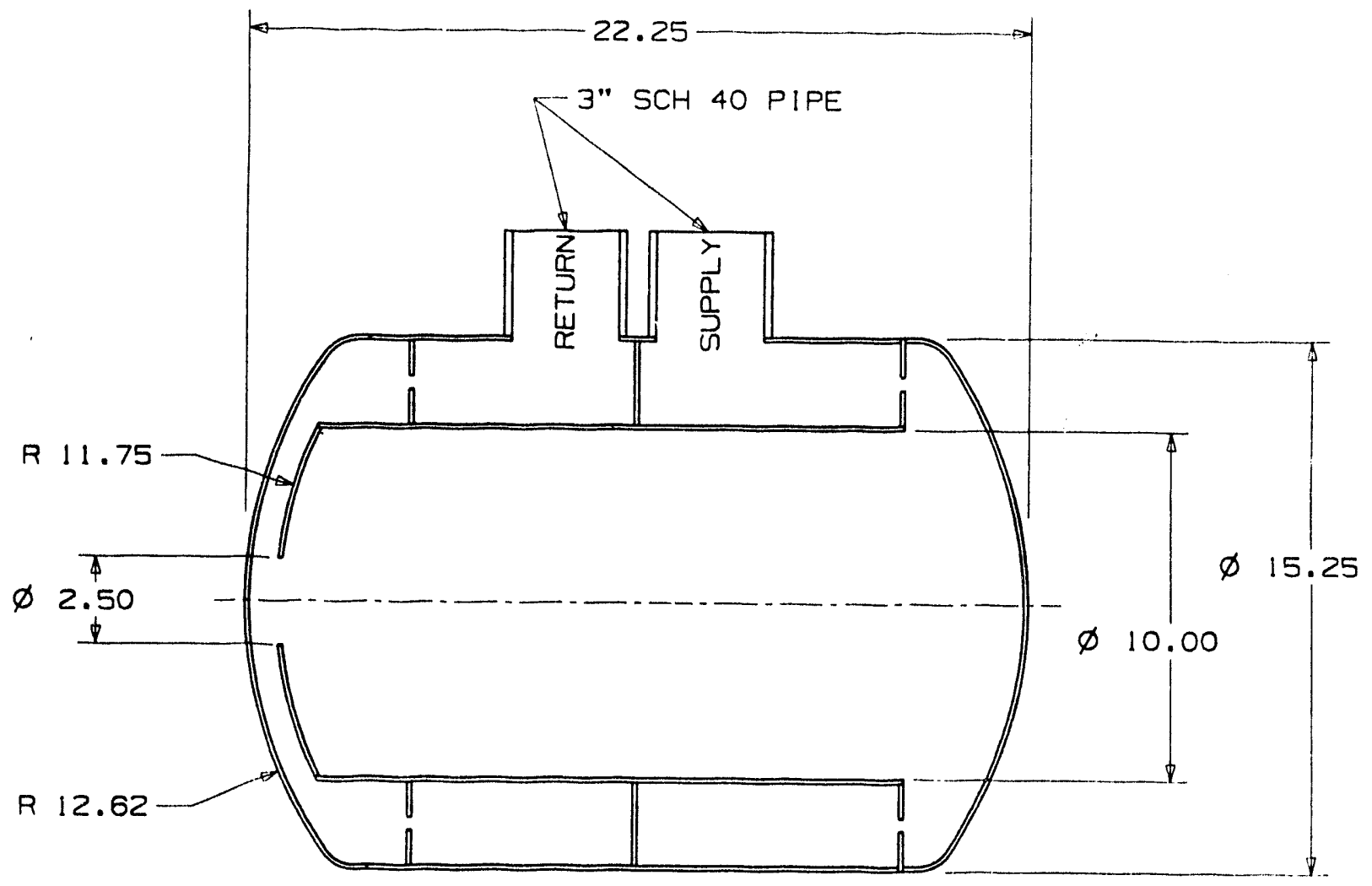

Fig. 1 Diagram of the primary spallation target.

41

82

123

164 Wat 205 246

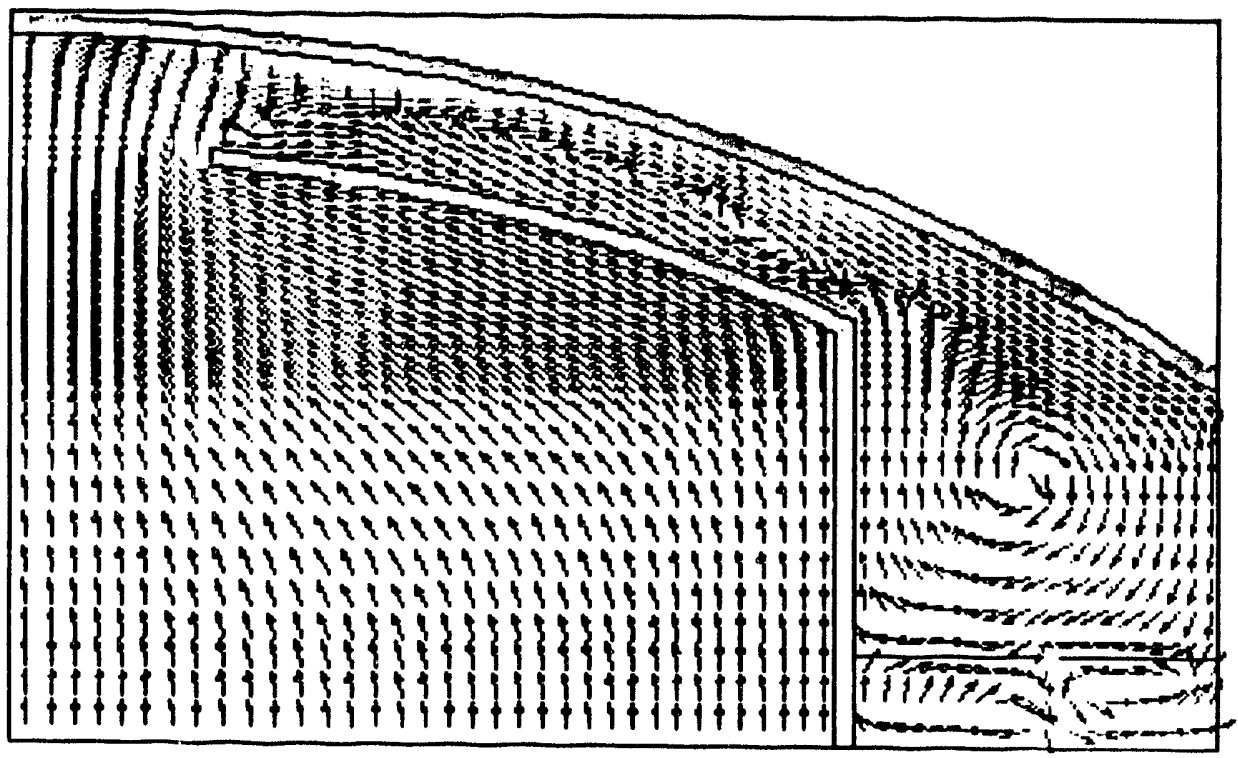

Fig. 2. Flow characterization of the lead flow between the two windows with velocity vectors $(\mathrm{cm} / \mathrm{sec})$ included. 


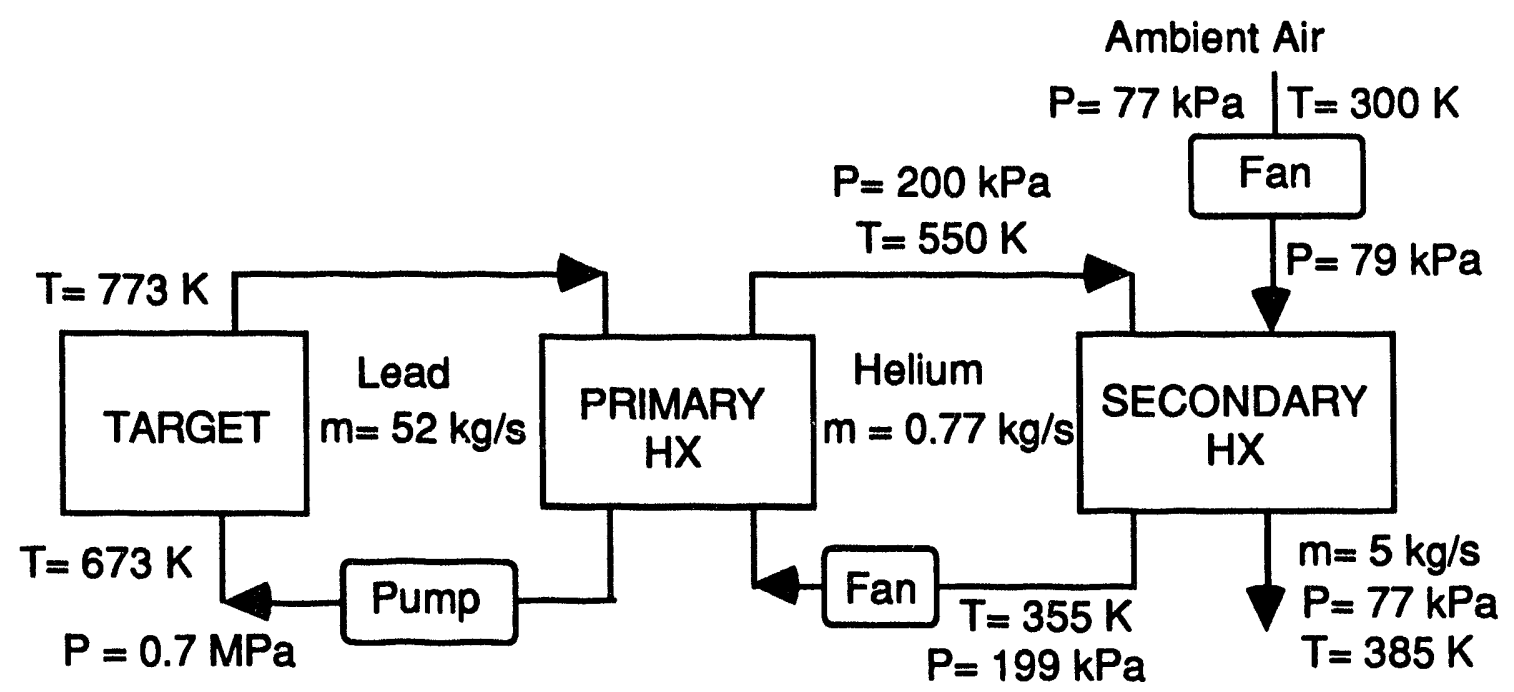

Target Thermal Power $=800 \mathrm{~kW}$

Fig.3. Operating conditions for lead target system.

concentric annuli. The peak power density occurs in the center of the beam and is equal to approximately $2000 \mathrm{~W} / \mathrm{cc}$. A best estimate of heat transfer coefficient for direct impingement cooling on the target window with flow through a $6.35-\mathrm{cm}$ diameter hole is $17400 \mathrm{~W} / \mathrm{m}^{2}-\mathrm{K}$. This is based in flow impinging on a large diameter sphere, whereas the actual flow condition looks more like a submerged jet impingement. Therefore, there is a large uncertainty in this prediction, and there is no correlation in the literature for a liquid metal from a better geometry match. With this coefficient, and at $450 \mathrm{~W} / \mathrm{cm}^{2}$ surface heat flux (resulting from $2000 \mathrm{~W} / \mathrm{cc}$ in a $0.24 \mathrm{~cm}$ thick window), the inside window temperature will be $775^{\circ} \mathrm{C}$ at a $\mathrm{Pb}$ temperature of $500^{\circ} \mathrm{C}$. The temperature gradient through the window is $100^{\circ} \mathrm{C}$, resulting in a peak window temperature of $875^{\circ} \mathrm{C}$. Issues such as wetting and effects of gases or other impurities are recognized as serious issues in maintaining the required heat removal from the structure. These issues can not be resolved satisfactorily through analytical techniques, however, and (as will be described later) are included in the developmental experiments which precede the final spallation target operation.

The intermediate heat exchanger has the lead contained within the shell and the secondary fluid (helium) flowing within the tubes. The lead is contained within the shell so as to provide easier draining and eliminate the chance of plugging the tubes' interior bore. The tubes are formed in a U-tube shape to aid in absorbing thermal expansion. The heat exchanger is designed to transfer $800 \mathrm{~kW}$ of heat with an additional over-capacity factor of $35 \%$. Calculations include an allowance for compressive heating of the helium by the blower. Helium enters through a duct in the side of the assembly at $102{ }^{\circ} \mathrm{C}$ and flows at an average velocity of $134 \mathrm{~m} / \mathrm{s}$ downward on one side of the U-tubes, and then flows upward on the other side and exits at a temperature of $277^{\circ} \mathrm{C}$ back out the side horizontally. The liquid lead enters at a temperature of $500^{\circ} \mathrm{C}$ through distribution pipes at the rear of the tube bundle and flows forward in crossflow across the tubes, making a single pass, and then exiting at a temperature of $400{ }^{\circ} \mathrm{C}$ at the front through another set of distribution pipes. Because the heat conduction of the lead to the tubes is much better than the heat conduction of the helium to the tubes, the lead flows at a relatively low average velocity of $0.07 \mathrm{~m} / \mathrm{s}$. 
A compact plate-fin cross-flow heat exchanger transfers heat from the secondary cooling loop to the ambient environment. The secondary cooling loop pressure and temperature at the compact heat exchanger inlet are $200 \mathrm{kPa}$ and $277^{\circ} \mathrm{C}$ temperature. Several heat exchanger candidate designs have been examined to maximize heat exchanger effectiveness with minimum pressure drop and heat exchanger size. A typical heat exchanger configuration has an exit temperature of $75^{\circ} \mathrm{C}$ with a $840 \mathrm{~Pa}$ pressure drop. The power requirement for the secondary loop heat exchangers is about $50 \mathrm{~kW}$ for a blower with a 50 percent adiabatic efficiency. The heat exchanger is cooled with ambient air supplied by a blower. After passing through the heat exchanger the heated air is exhausted to the atmosphere. The required power for the air blower with 50 percent adiabatic efficiency assuming a $77 \mathrm{kPa}$ inlet pressure, a $1770 \mathrm{~Pa}$ static pressure rise, and a $5 \mathrm{~kg} / \mathrm{s}$ mass flow rate is about $20 \mathrm{~kW}$.

Lead circulation in the ADTT experimental target will be produced using an A. C. electromagnetic (EM) conduction pump. EM pumps offer the advantage of being nonintrusive to the piping; no seals or mechanical coupling to the lead are necessary. The selected pump will circulate the lead at the required $52 \mathrm{~kg} / \mathrm{s}$ with a 20 psi pressure boost at an efficiency of $11 \%$. Physically, the pump is approximately cubical, 22 inches on a side, and weighs $360 \mathrm{lb}$.

\section{LEAD HANDLING SYSTEM}

To facilitate safe and efficient handling of the lead, only liquid lead will be used in the primary target system. Thaw, freeze and lead storage will be performed below (allowing gravity drainage) the primary target system in a "reservoir" specifically designed for this purpose. Outside the primary target system the lead is handled in a "foundry" of similar design (but twice the volume) to the "reservoir". A diagram of the foundry is shown in Fig. 4 and the features of the reservoir can be seen in Fig. 5. In each, heaters are located around the sides and bottom of the lead in clusters or zones to allow for spatially dependent heating of the lead. A free surface of lead at the top accommodates the increase in volume (3\%) and any lead oxide that might form. The heaters in the foundry produce $20 \mathrm{~kW}$ allowing for a 4 hour melt. In the reservoir they produce $10 \mathrm{~kW}$ which translates into a 6.6-hour period to melt the volume of lead to an operational temperature $\left(450^{\circ} \mathrm{C}\right)$ prior to injection, including estimates for heat losses to the vessel and surrounding environment. In both systems lead is maintained in an argon atmosphere to minimize the formation of lead oxide which can prohibit flow. Initially, the lead is 0.9999 pure; this purity is commercially available[3]. Also, lead injected into the primary target system is taken form the bottom of the foundry or reservoir to help reduce injection of any oxide into the system because the less-dense oxide will float on the top of the free-surface in both the foundry and the reservoir. The lead is injected using argon pressure into the target system initially from the foundry and subsequently from the reservoir. A level sensor located at the top of the primary loop detects when the system is full, closing a pneumatic valve and separating the primary loop from the reservoir. These features can be seen in Fig. 5 . The valve can be remotely operated to drain the lead into the reservoir for storage and freezing. The valve will automatically open during off-normal conditions to drain the lead from the system. Lead can be pumped outside the target chamber, from the reservoir to the foundry, using argon pressurization.

\section{INSTRUMENTATION}

The planned instrumentation is also shown in Fig. 5. The ADTT instrumentation will be centered around dual personal computers (PCs) with one PC running in hot standby mode. A heartbeat between the two PCs will provide automatic switchover in case the active computer should fail. All interfaces to temperature sensors, level detectors, etc. will be handled through standard process control boards plugged into the PC. The hardware will use off-the-shelf products wherever possible. All process control and user interface will be handled in LabView. LabView is a process control/programming environment that allows maximum flexibility in 


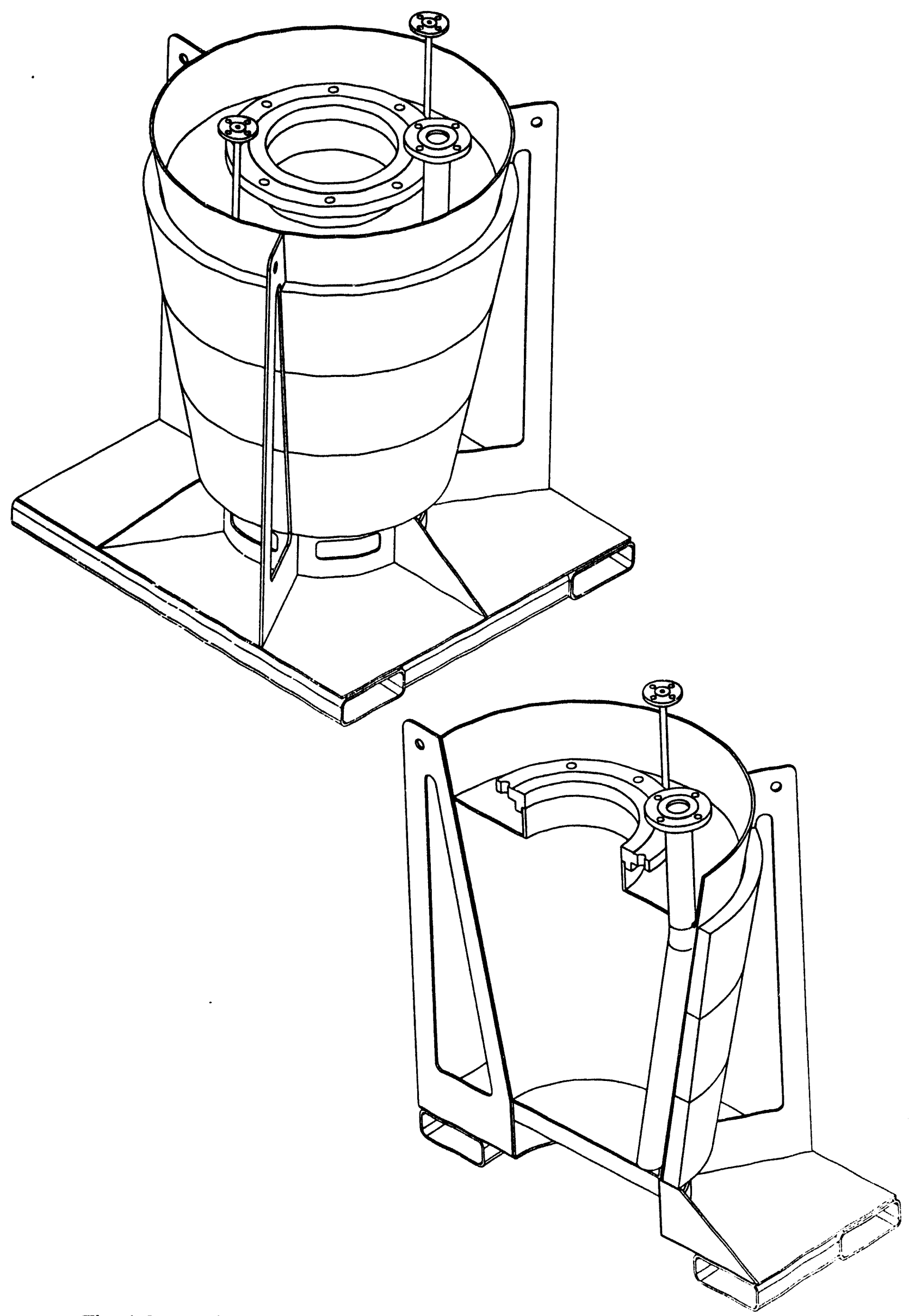

Fig. 4 Isometric views (solid and cut-away) of lead foundry. The resevoir is of similar design, but smaller. 


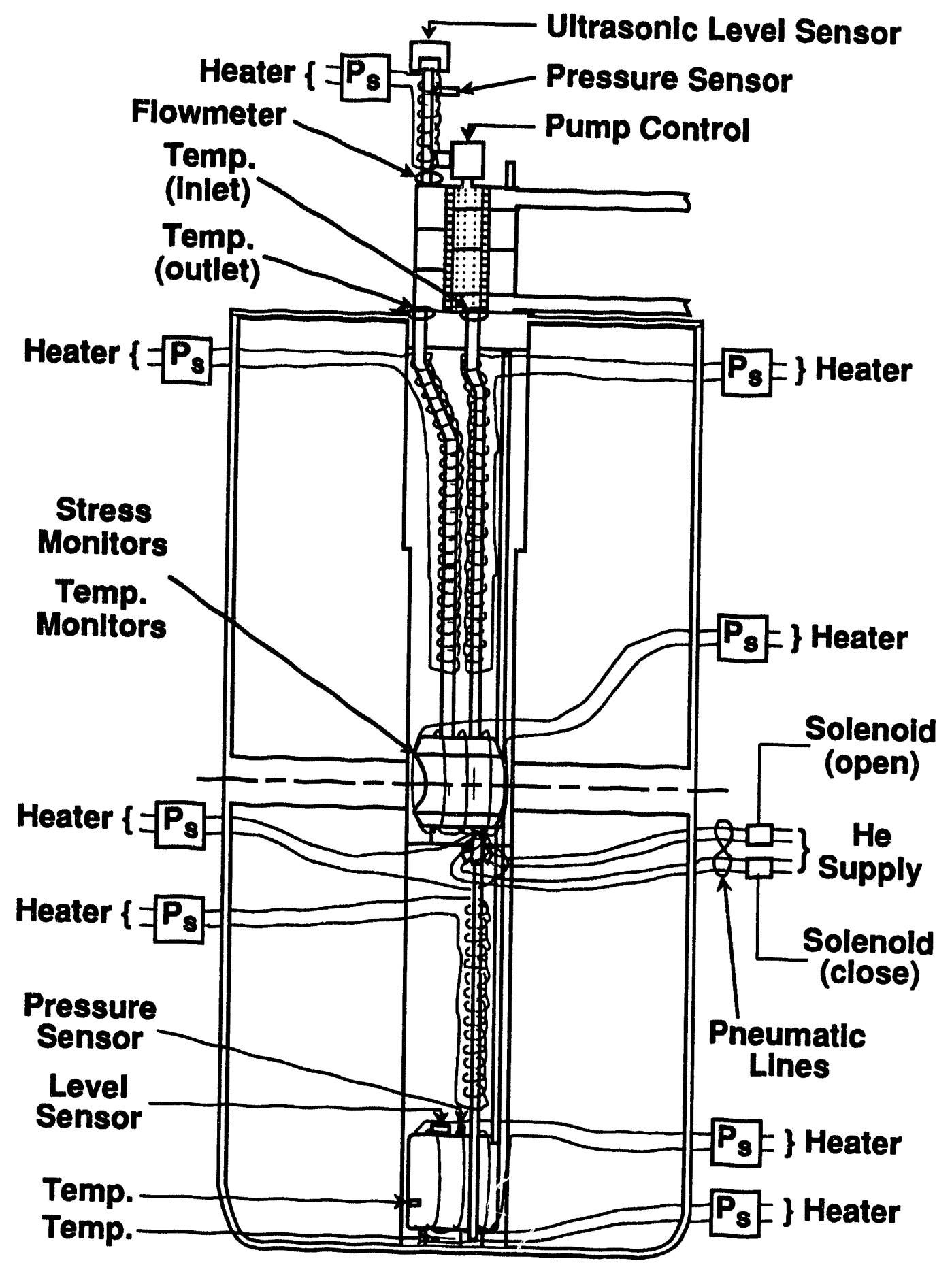
Fig. 5. Diagram of experimental target system showing primary target loop, lead reservoir, and
planned instrumentation 
modifying the process when needed. At the same time, a process flow chart can be easily implemented that maintains safety of operation by not allowing process actions that could result in unintended results. As an added safety measure, both audible and visual alarms will be controlled from within LabView.

\section{DEVELOPMENTAL EXPERIMENTS}

Prior to the final operation of the experimental target, a number of developmental experiments are planned. The purpose of these experiments is to eliminate as many uncertainties as possible prior to the final target operation that can not be eliminated through analysis, as well as benchmark the analytical techniques used in the target design.

\section{Irradiation Experiments}

Although the high temperature strength of $\mathrm{Nb}-1 \mathrm{Zr}$ is well characterized, both unirradiated and thermal-reactor irradiated, its long term behavior in a mixed proton and high energy neutron environment is unknown. The effect of irradiation on surface topology will also impact $\mathrm{Pb}$ wetting and heat transfer. Consequently, several material irradiation experiments are planned which address the irradiated strength of $\mathrm{Nb}-1 \mathrm{Zr}$ :

\section{Neutron Irradiation of TEM Samples}

TEM samples in a sample holder will be irradiated at LAMPF in neutron-irradiation ports. The irradiated TEM samples will be used for subsequent micro-hardness testing, surface examination, and Transmission Electron Microscopy (TEM). Material damage induced by the entire spallation neutron flux spectrum can be estimated from the results of this experiment. The calculated spallation neutron flux from the LAMPF A-6 target station differs from the fission flux in two ways: there is a high energy tail above $5 \mathrm{MeV}$ and there is an increased flux component below approximately $0.1 \mathrm{MeV}$; both of these are not present in a fission flux.

\section{Proton Irradiation}

In order to expose material samples directly to a high-energy $(700-800 \mathrm{MeV})$ proton flux, thin sheet samples will be inserted into a standard isotope production stringer. The irradiated samples will be used for subsequent micro hardness test, tensile test, and TEM microscopy to identify the material damage induced by protons. Depending on sample location within a stringer and the stringers relative position to other stringers, nearly prototypic proton and neutron conditions can be achieved.

\section{Thermal-Hydraulic Experiments}

Key to the performance and lifetime of the active target region is the ability of the flowing lead to cool the window and other important locations within the active target region. Locating stagnation points and predicting flow patterns within the complex geometry of the target is very important and analytical predictions for the lead system must be validated experimentally. Another uncertainty stems from the inability of lead to readily wet surfaces. Heat transfer coefficient correlations are sometimes $50 \%$ lower for lead than predicted for lighter liquid metals. This fact, coupled with the target's complex flow geometry, results in a large uncertainty in the ability of the lead to remove energy generated within the containment structure walls. Cleaning procedures and design features, such as surface polishing, may be used to enhance wetting and reduce surface resistivity. The following experiments are planned to quantify performance and eliminate these uncertainties. 
This experiment consists of a scaled model of the active target region constructed of Plexiglas. Room temperature water, or another applicable simulant fluid, will be circulated through the model and dye injection used to examine the flow topology throughout the target. Various dye injection locations will be us/d to validate analytical predictions to the extent that water has similar hydraulic characteristics as molten lead.

\section{Convective Heas Transfer Test with Flowing Pb}

This experiment will consist $o:$ a forced convection molten lead loop centered around a test fixture. The fixture will be heated and relevant heat transfer coefficient measurements will be made. In addition, the effects of wetting and gas build-up will be characterized.

\section{Full-Scale, Fully Instrumented Flowing Pb Loop (w/o Nb-1Zr)}

This purpose of this test is to qualify the target by repeated operation of a liquid-lead loop through all anticipated normal events (such as drain, rethaw, refill, and drain) and anticipated offnormal events (such as drain valve failure or loss of cooling). The system will be fully instrumented with pressure transducers, thermocouples, strain gauges, and flow meters and can be constructed of non-prototypic material such as ferritic steel. Included in this test will be a pretest of the experimental target with $R F$ and $I^{2} R$ heating used to simulate actual heating conditions.

\section{CONCLUSIONS}

Preliminary analyses with regard to an experimental flowing-lead spallation target to be located at LAMPF have been performed. While many technical issues remain to be resolved either through further calculations or experimentally, no serious deficiencies have been identified. Safe and reliable operation of the target has been maximized through simple, robust engineering, and a developmental experimental program has been identified to resolve the majority of design uncertainties before final operation of the target in the proton beam. The successful completion of this experimental program will be a key component in proving the practical feasibility of ADTT systems.

\section{REFERENCES}

[1] Park, J. J., et al., "Selection of Structural Materials for Flowing Liquid Lead Target for the Accelerator Based Conversion of Plutonium/Accelerator Transmutation of Waste," this conference, 1994.

[2] Prael, R. E., and Lichtenstein, H., "User Guide to LCS: The LAHET Code System," Los Alamos National Laboratory document LA-UR-89-3014 (September 1989).

[3] DOE RUN Inc., personal communication (1994). 

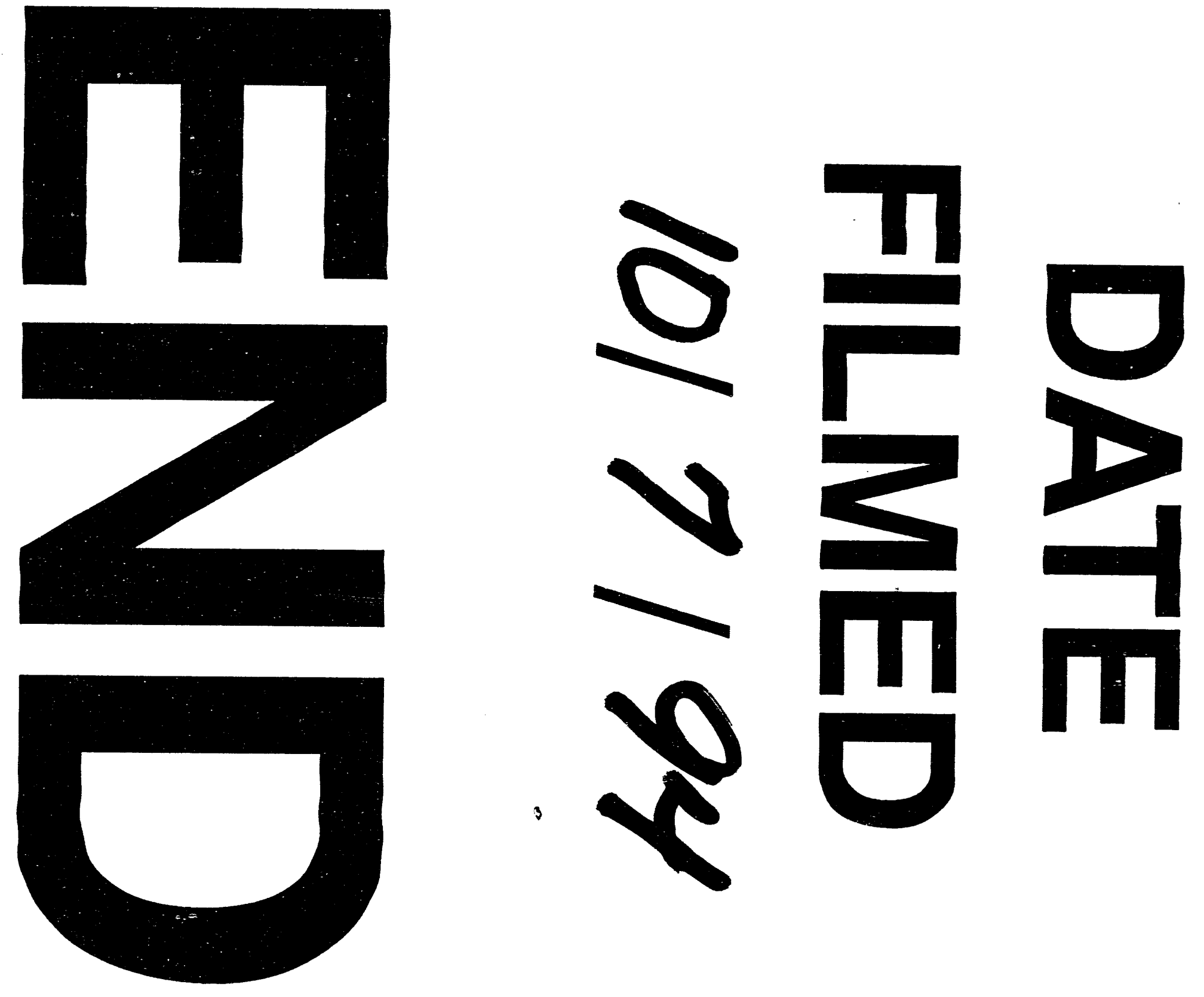